\title{
Combined PI3K and CDK2 inhibition induces cell death and enhances in vivo antitumour activity in colorectal cancer
}

\author{
Gary Beale ${ }^{1}$, Emma J Haagensen ${ }^{1}$, Huw D Thomas ${ }^{1}$, Lan-Zhen Wang ${ }^{1}$, Charlotte H Revill ${ }^{2}$, Sara L Payne ${ }^{2}$, \\ Bernard T Golding ${ }^{2}$, lan R Hardcastle ${ }^{2}$, David R Newell ${ }^{1}$, Roger J Griffin ${ }^{2, *}$ and Celine Cano ${ }^{* 2}$ \\ ${ }^{1}$ Newcastle Cancer Centre, Northern Institute for Cancer Research, Paul O'Gorman Building, Medical School, Newcastle \\ University, Framlington Place, Newcastle-upon-Tyne NE2 4HH, UK and ${ }^{2}$ Newcastle Cancer Centre, Northern Institute for Cancer \\ Research, School of Chemistry, Newcastle University, Bedson Building, Newcastle NE1 7RU, UK
}

Background: The phosphatidylinositol-3-kinase/mammalian target of rapamycin (PI3K/mTOR) pathway is commonly deregulated in human cancer, hence many PI3K and mTOR inhibitors have been developed and have now reached clinical trials. Similarly, CDKs have been investigated as cancer drug targets.

\begin{abstract}
Methods: We have synthesised and characterised a series of 6-aminopyrimidines identified from a kinase screen that inhibit PI3K and/or mTOR and/or CDK2. Kinase inhibition, tumour cell growth, cell cycle distribution, cytotoxicity and signalling experiments were undertaken in HCT116 and HT29 colorectal cancer cell lines, and in vivo HT29 efficacy studies.

Results: 2,6-Diaminopyrimidines with an $\mathrm{O}^{4}$-cyclohexylmethyl substituent and a C-5-nitroso or cyano group (1,2,5) induced cell cycle phase alterations and were growth inhibitory $\left(\mathrm{Gl}_{50}<20 \mu \mathrm{m}\right)$. Compound 1, but not 2 or 5 , potently inhibits $\mathrm{CDK}_{2}\left(\mathrm{IC} \mathrm{C}_{50}=0.1\right.$ $\mathrm{nm}$ ) as well as PI3K, and was cytotoxic at growth inhibitory concentrations. Consistent with kinase inhibition data, compound 1 reduced phospho-Rb and phospho-rS6 at GI 50 concentrations. Combination of NU6102 (CDK2 inhibitor) and pictilisib (GDC-0941; pan-PI3K inhibitor) resulted in synergistic growth inhibition, and enhanced cytotoxicity in HT29 cells in vitro and HT29 tumour growth inhibition in vivo.
\end{abstract}

Conclusions: These studies identified a novel series of mixed CDK2/PI3K inhibitors and demonstrate that dual targeting of CDK2 and PI3K can result in enhanced antitumour activity.

Insights into the molecular pathology of cancer have resulted in the development of targeted approaches for cancer therapy. The phosphatidylinositol-3-kinase/mammalian target of rapamycin (PI3K/ mTOR) pathway is one of the most commonly deregulated pathways in human cancer in which signals are transduced via a cascade of lipid and serine/threonine kinases resulting in diverse effects on proliferation, apoptosis, protein translation, DNA repair, survival and transformation (for review see (Mayer and Arteaga, 2015)). Activation of receptor tyrosine kinases (RTKs) stimulates the PI3K pathway via adapter proteins, and PI3K phosphorylates phosphoinositide-3,4-biphosphate
$\left(\mathrm{PIP}_{2}\right)$ to generate $\mathrm{PIP}_{3}$ that activates $\mathrm{AKT}(\mathrm{PKB})$. AKT has many functions including roles in cell migration, apoptosis and glucose uptake, and the activation of mTOR via downregulation of the TSC1/ Rheb complex. mTOR in a complex with Raptor (to form mTORC1) signals via p70S6 kinase and 4EBP1 to regulate the translation of proteins and cell growth. mTOR also complexes with Rictor (to form mTORC2) to activate AKT. Negative feedback occurs at many nodes in the PI3K/mTOR cascade, most notably by PTEN and by S6 kinasemediated regulation of RTK signalling, for example, by downregulation of IRS-1 (Harrington et al, 2005). 
Activating mutations in the PIK3CA (p110 $\alpha$ ) isoform of PI3 kinase are observed in a wide range of tumours including breast, colon, glioblastoma and ovarian cancers (Cancer Genome Atlas Research Network, 2008; Stemke-Hale et al, 2008; Mayer and Arteaga, 2015), and inactivation of the tumour suppressor protein PTEN has been documented in, among others, glioblastoma, breast cancer, prostate cancer and melanoma (Cairns et al, 1997; Garcia et al, 1999; Celebi et al, 2000; Cancer Genome Atlas Research Network, 2008). More rarely AKT mutations or amplifications have been detected in colorectal, head and neck, pancreatic and breast tumours, and large a proportion of cancers have activation of mTORC1 as demonstrated by increased phosphorylation of proteins such as S6 kinase, 4EBP1, ribosomal S6 protein and mTOR itself (reviewed in (Menon and Manning, 2008)).

Considerable effort has been focussed on the development of PI3K/mTOR pathway inhibitors, many of which have now reached clinical trials (Yap et al, 2015). Rapamycin, discovered as an antifungal agent from Streptomyces hygroscopicus, was the first mTOR inhibitor characterised and a number of the trial candidates are rapamycin analogues (rapalogues). Rapamycin binds to FKbinding protein 12 and therefore only inhibits the mTORC1 complex and not mTORC2. Rapamycin has been approved for the treatment of advanced renal cell carcinoma and, following promising Phase III trials, the rapalogues temsirolimus and everolimus have been approved for renal cell carcinoma and soft tissue/bone sarcomas, respectively (Chiarini et al, 2015). In addition, compounds are in clinical trials that block both mTORC1 and mTORC2 by competitive inhibition at the ATP-binding site (Chiarini et al, 2015).

ATP competitive inhibitors of PI3 kinase have also entered clinical trials (Chiarini et al, 2015). These compounds mainly target the $\mathrm{p} 110 \alpha$ isoform of PI3K, but some have been developed that have selectivity for other isoforms, for example, idelalisib inhibits $\mathrm{p} 110 \delta$ but not $\alpha$ or $\beta$ (Lannutti et al, 2011). Compounds such as dactolisib target PI3K and mTOR at similar potency, and others such as pictilisib are pan-PI3K inhibitors (Brachmann et al, 2009). A review of published early clinical trial data indicates that PI3K inhibitors are well tolerated and as single agents they can induce disease stabilisation, and in some cases regression (Brachmann et al, 2009; Engelman, 2009). Preclinical data suggest that combinations of PI3K inhibitors with other targeted therapies, for example, MEK inhibitors (Engelman et al, 2008; Haagensen et al, 2012; Haagensen et al, 2013), can result in significant synergism and clinical trials to explore such combinations are ongoing.

Cyclin-dependent kinases (CDKs) regulate cell cycle progression and transcription via sequential interaction with specific cyclins. In some cancers defects in the expression of CDKs and their regulatory proteins, for example, loss of $\mathrm{CDK}$ inhibitors or upregulation of cyclin expression, leads to aberrant regulation of the cell cycle (Satyanarayana and Kaldis, 2009). CDK2 has an important role in the G1 to S-phase transition and also has a role in S-phase progression. In particular, phosphorylation of Retinoblastoma protein $(\mathrm{Rb})$ by cyclin $\mathrm{D} / \mathrm{CDK} 4$ and 6 complexes, followed by the cyclin E/CDK2 complex, inactivates $\mathrm{Rb}$ releasing $\mathrm{E} 2 \mathrm{~F}$ and thereby promoting S-phase entry and progression (Harbour et al, 1999; Aleem et al, 2004). Numerous small molecule inhibitors of CDKs have been evaluated in clinical trials (Shapiro, 2006; Asghar et al, 2015), some of which are pan-CDK inhibitors such as flavopiridol, whereas other compounds are more selective. Preliminary clinical data with $\mathrm{CDK}$ inhibitors suggests they are generally well tolerated but rarely induce marked anti-proliferative toxicity or tumour regressions when given as single agents (Shapiro, 2006; Asghar et al, 2015). Thus, with the exception of flavopiridol for the treatment of chronic lymphocytic leukaemia (Lin et al, 2009), where the transcriptional kinase CDK9 is thought to be the primary target, and palbociclib for the management of ER-positive HER2-negative breast cancer, where CDK4/6 is the target (Rocca et al, 2014), it has yet to be determined whether CDK-specific or pan-CDK inhibitors are preferable (Shapiro, 2006), or indeed if this compound class generally possesses widespread antitumour activity.

In a counter-screen of compounds designed to inhibit CDK2 we identified a number of molecules that were also mTOR and/or PI3 kinase inhibitors. These compounds provided an opportunity to evaluate the impact of simultaneous modulation of cell cycle and survival/growth signalling, via dual $\mathrm{CDK}$ and $\mathrm{PI} 3 \mathrm{~K} / \mathrm{mTOR}$ inhibition, which revealed that potent CDK2 inhibition combined with PI3K inhibition resulted in cell cycle and growth inhibition, and cytotoxicity. In vitro results with a dual CDK/PI3K inhibitor were recapitulated using a combination of a selective CDK2 inhibitor (NU6102) and a pan-PI3K inhibitor (pictilisib), and extended to in vivo studies that showed enhanced tumour growth inhibition with the drug combination.

\section{MATERIALS AND METHODS}

Materials. Dactolisib and pictilisib were purchased from Stratech Scientific (Suffolk, UK) and rapamycin from Merck (Nottingham, UK). Anti phospho-4EBP1 (Cat\# 2855S), 4EBP1 (Cat\# 9644), phospho-AKT (Cat\# 4060S), AKT (Cat\# 4691S), phosphoribosomal S6 (Cat\# 4858S) and ribosomal S6 (Cat\# 2217S) antibodies were purchased from NEB (Hitchin, UK). Anti phospho-Rb (Cat\# 44-582 G) was supplied by Invitrogen (Paisley, $\mathrm{UK}$ ) and anti-Rb (Cat\# 554136) by BD Biosciences (Oxford, UK). All other reagents were analytical grade where available and supplied by Sigma (Gillingham, UK).

Synthesis of compounds. The following compounds were synthesised as previously described: 1 (Sayle et al, 2003), 2 (Arris et al, 2000), 3 and 4 (Mesguiche et al, 2003), 5 and 6 (Marchetti et al, 2010). 7 and 8 were synthesised as described in Supplementary Material. NU6102 (4-[[6-(cyclohexylmethoxy)-9H-purin-2-yl]amino]-benzenesulfonamide) was synthesised as previously described (Davies et al, 2002).

Enzyme assays. PI3Ks (Condliffe et al, 2005) and CDK2 (Arris et al, 2000) assays were performed as previously described. The inhibition of mTOR kinase activity at $10 \mu \mathrm{M}$ ATP was measured by TR-FRET according to the manufacturer's instructions (http://tools.invitrogen.com/Content/SFS/lanthascreen/ PV4753\%20FRAP1\%20Assay\%20Validation.pdf).

Cell culture. HCT116 and HT29 cells were obtained from ATCC (Teddington, UK), and grown in DMEM supplemented with $10 \%$ $(\mathrm{v} / \mathrm{v})$ fetal bovine serum, 100 units $\mathrm{ml}^{-1}$ penicillin, $0.1 \mathrm{mg} \mathrm{ml}^{-1}$ streptomycin and $2 \mathrm{~mm}$ L-glutamine.

Cell growth inhibition assays. Cells were trypsinised and plated in 96-well plates at a seeding density of 1000 cells per well. Twentyfour hours later cells were incubated for $72 \mathrm{~h}$ with $0.001-100 \mu \mathrm{M}$ of each inhibitor dissolved in DMSO with a final DMSO concentration of $1 \%(\mathrm{v} / \mathrm{v})$. Cells were fixed with $50 \%(\mathrm{w} / \mathrm{v})$ TCA and stained with $0.4 \%(\mathrm{w} / \mathrm{v})$ sulforhodamine B (SRB) for $30 \mathrm{~min}$ before washing with $1 \%(\mathrm{v} / \mathrm{v})$ acetic acid. SRB was solubilised with $10 \mathrm{~mm}$ Tris $\mathrm{pH} 10.5$, the absorbance read at $570 \mathrm{~nm}$, and cell growth expressed as \% of the growth of cells exposed to $1 \%(\mathrm{v} / \mathrm{v})$ DMSO. The concentration of compound that resulted in 50\% growth inhibition $\left(\mathrm{GI}_{50}\right)$ was calculated by interpolation from the growth inhibition/concentration curves using GraphPad Prism software (La Jolla, USA). Combination growth inhibition studies of NU6102 and pictilisib were performed as previously described (Haagensen et al, 2012).

Clonogenic assays. Cells were seeded in six-well plates at a density of $1 \times 10^{5}$ per well and allowed to adhere overnight. The $\mathrm{GI}_{50}$ 
concentration from the SRB assay for the pyrimidine compounds 1-8 was added to the cells for 8 or $72 \mathrm{~h}$. Cells were washed twice with PBS before the addition of standard growth medium. Following incubation to allow colony ( $>50$ cells) formation, cells were fixed with Carnoy's solution and stained with $0.4 \%(\mathrm{w} / \mathrm{v})$ crystal violet solution for $1 \mathrm{~h}$. Colonies were washed with $1 \%(\mathrm{v} / \mathrm{v})$ acetic acid and counted using an Oxford Optronix Colcount (Oxford, UK). Single agent and combination cytotoxicity studies with NU6102 and pictilisib at 1 or $10 \mu \mathrm{m}$ were performed using the same method with cells being exposed to drugs for $72 \mathrm{~h}$ before plating out for colony formation. Statistical analyses were performed using ANOVA.

Flow cytometry. Cells were seeded in six-well plates at a density of $4 \times 10^{5}$ per well and allowed to adhere overnight. Incubation of the cells with the $\mathrm{GI}_{50}$ concentration of each compound for up to $24 \mathrm{~h}$, was followed by washing with PBS and cell removal with trypsin. Trypsinised cells were centrifuged, washed with PBS and fixed with $75 \%$ ethanol/25\% PBS (v/v) overnight. Pellets were rehydrated with PBS and stained using $1 \mathrm{mg} \mathrm{m}^{-1}$ RNase and $400 \mathrm{mg} \mathrm{ml}^{-1}$ propidium iodide for $4 \mathrm{~h}$, and analysed using a Becton Dickinson FACSscan and Cellquest software (BD biosciences) with data evaluation using WinMdi software (http://facs.scripps.edu/ software.html) and ANOVA statistical analysis.

Western blotting. Cells were seeded in six-well plates at a density of $4 \times 10^{5}$ per well and allowed to adhere overnight. Cells were incubated with $0.5,5$ or $50 \mu \mathrm{M} 1$ or 5 for 4,8 or $24 \mathrm{~h}$ before being washed and extracted with Phosphosafe buffer (Merck). Protein concentrations were determined by bicinchoninic acid assay (Thermo Scientific, Cramlington, UK) and $30 \mu \mathrm{g}$ of total protein for each sample was loaded into the wells of a 4-20\% tris-glycine Novex gel (Invitrogen). Proteins were resolved at $120 \mathrm{~V}$ for $\sim 2 \mathrm{~h}$ before being transferred to Hybond-C nitrocellulose (GE Healthcare, Chalfont St Giles, UK). Membranes were probed with the appropriate dilution of antibody overnight and, after washing, the appropriate secondary antibody used at a dilution of $1: 1000$, followed by analysis using Supersignal West Dura enhanced chemiluminescence substrate (Thermo Scientific).

In vivo studies. All of the in vivo experiments were reviewed and approved by the institutional animal welfare committee, and performed according to the United Kingdom Coordinating Committee on Cancer Research (UKCCCR) Guidelines for the Welfare of Animals in Experimental Neoplasia (second edition) and national law. CD-1 nude mice (Charles River, Ramsgate, Kent, UK) were implanted with $1 \times 10^{7}$ HT29 cells, in a mixture of Matrigel/RPMI cell culture media $(1: 1 \mathrm{v} / \mathrm{v})$, subcutaneously on the right flank. Tumours were allowed to develop until they were palpable $(\sim 0.5 \times 0.5 \mathrm{~cm}, 10-12$ days after implantation) and randomised into four treatment groups (six animals per group).
Mice were treated with vehicle (control), NU6301 $120 \mathrm{mg} \mathrm{kg}^{-1}$ i.p. (a water soluble prodrug of NU6102 (Thomas et al, 2011); $120 \mathrm{mg} / \mathrm{kg}^{-1} \mathrm{NU} 6301$ being equivalent to $100 \mathrm{mg} \mathrm{kg}^{-1} \mathrm{NU6102)}$ twice daily, $100 \mathrm{mg} \mathrm{kg}^{-1}$ pictilisib p.o. once daily, or the combination of twice daily NU6301 (120 $\mathrm{mg} \mathrm{kg}^{-1}$ i.p.) and once daily pictilisib (100 $\mathrm{mg} \mathrm{kg}^{-1}$ p.o.) for 10 days. Tumour volume was calculated from two-dimensional calliper measurements using the equation $a^{2} \times b / 2$, where $a$ is the smallest measurement and $b$ the largest. Data are presented as median relative tumour volumes (RTV), where the tumour volume on the initial day of treatment (day 0) is assigned an RTV value of 1 in accordance with the formula: RTV = tumour volume on day of observation/tumour volume on day 0 . Statistical analyses of the effects of drug treatment was undertaken using the Mann-Whitney test.

\section{RESULTS}

The structures of the compounds tested are shown in Supplementary Figure 1 and their activity as inhibitors of CDK2, the four PI3K isoforms and $\mathrm{mTOR}$ in purified kinase assays is shown in Table 1; ranked in order of potency as inhibitors of CDK2. Sulphonamide $\mathbf{1}$ is an extremely potent inhibitor of CDK2 $\left(\mathrm{IC}_{50} 0.1 \mathrm{nM}\right)$ and a low $\mu \mathrm{M}$ inhibitor of all of the PI3K isoforms with the exception of PI3K $\beta$. However, 1 did not inhibit mTOR at the highest concentration tested $(20 \mu \mathrm{M})$. The parent compound in this series, 2, inhibited CDK2 and all of the PI3K isoforms at similar concentrations $(1-10 \mu \mathrm{M})$, but was somewhat less potent against mTOR. The cyano compound 7 has $\mathrm{IC}_{50}$ values in the range $10-20 \mu \mathrm{m}$ for $\mathrm{CDK} 2$ and the $\mathrm{PI} 3 \mathrm{~K} \alpha, \delta$ and $\gamma$ isozymes, but like $\mathbf{1}$ is less active against $\mathrm{PI} 3 \mathrm{~K} \beta$ and mTOR. The nitroso compound $\mathbf{6}$ is similar to 7, although somewhat less active against CDK2 and more active against PI3Ks $\alpha, \delta$ and $\gamma$. The aldehyde 4 and cyano compound 5 are similar to $\mathbf{6}$, although $\mathbf{4}$ is distinct in having an $\mathrm{IC}_{50}$ for mTOR of $15 \mu \mathrm{M}, v s<5 \%$ inhibition for $\mathbf{6}$ and $\mathbf{5}$ at $20 \mu \mathrm{m}$. Also, 5 is less active than $\mathbf{6}$ and $\mathbf{4}$ against CDK2. Importantly, the $\mathrm{O}^{4}$-(4-chlorobenzyl) compound $\mathbf{8}$ did not inhibit CDK2 but is an inhibitor of all four PI3K isozymes and mTOR, whereas 3 is only active against mTOR ( $\left.\mathrm{IC}_{50} 13 \mu \mathrm{M}\right)$.

The cell growth inhibitory activity of each compound was tested using the SRB assay in HCT116 and HT29 cells. GI $_{50}$ values were calculated from the mean of three separate assays for each compound, and are given in Table 2. Rapamycin, dactolisib (NVPBEZ235), pictilisib (GDC-0941; pictrelisib) and NU6102 were used as positive controls for mTOR inhibition, dual PI3K and mTOR inhibition, pan-PI3K inhibition and CDK2 inhibition, respectively. Compounds 1, 2 and 5 were equipotent in both cell lines, similar in potency to rapamycin, but markedly less potent than the dual PI3K/mTOR inhibitor dactolisib. Inhibitors 4, 7 and 8 also had similar $\mathrm{GI}_{50}$ values, but were 5 -10-fold less potent at inhibiting cell

Table 1. Inhibition of CDK2, PI3K and mTOR kinases by 6-aminopyrimidines

\begin{tabular}{|c|c|c|c|c|c|c|}
\hline Compound & CDK2 & $\mathrm{PI} 3 \mathrm{~K} \alpha$ & $\mathrm{PI} 3 \mathrm{k} \boldsymbol{\beta}$ & PI3K $\delta$ & $\mathrm{PI} 3 \mathrm{~K} \gamma$ & mTOR \\
\hline 1 & $0.0001 \pm 0.00003$ & $3.6,6.2$ & $>20$ & $3.2,7.5$ & $3.7,6.8$ & $>20$ \\
\hline 2 & $2.2 \pm 0.5$ & $1.3,2.7$ & $5.7,11$ & $0.7,1.8$ & $1.5,2.1$ & 19 \\
\hline 7 & $9.6,13$ & $9.9,12$ & $>20$ & 12,14 & 18,20 & $>20$ \\
\hline 6 & $7.5,22$ & $2.9,4.4$ & $>20$ & $5.0,6.5$ & $2.9,7.1$ & $>20$ \\
\hline 4 & 22,24 & $5.4,11$ & $>20$ & $2.9,5.6$ & $1.7,5.3$ & 15 \\
\hline 5 & $60 \pm 10$ & $4.5,7.7$ & 18,23 & $6.9,5.9$ & $7.5,12$ & $>20$ \\
\hline 8 & $>>10$ & $2.5,6.2$ & $4.3,13$ & $0.5,1.1$ & $1.5,2.0$ & 4.9 \\
\hline 3 & $>>10$ & $>20$ & $>20$ & $>20$ & $>20$ & 13 \\
\hline
\end{tabular}

Abbreviations: $\mathrm{mTOR}=$ mammalian target of rapamycin; $\mathrm{PI} 3 \mathrm{~K}=$ phosphatidylinositol-3-kinase. Values are the $\mathrm{I}_{50}(\mu \mathrm{m})$ or the highest concentration tested $(\mu \mathrm{m})$, and are the mean $\pm \mathrm{s} . \mathrm{d}$. or individual determinations. For chemical structures see Supplementary Figure 1. 
growth than 1, 2 and 5. Growth inhibition induced by 3 and $\mathbf{6}$ did not reach $50 \%$ at $100 \mu \mathrm{M}$, inducing a maximum of $35 \%$ reduction in growth at $100 \mu \mathrm{m}$ in HCT116 cells.

The effects of the compounds on cell cycle phase distribution at $\mathrm{GI}_{50}$ concentrations, or at $100 \mu \mathrm{M}$ for $\mathbf{6}$ and $\mathbf{3}$, in asynchronous cultures were evaluated by flow cytometry in HCT116 cells (Figure 1A). An increase in the G1 population was observed, of varying magnitude, with 2,4 and 5 producing greater G1 phase accumulation than rapamycin or dactolisib (NVP-BEZ235). No effect on cell cycle phase distribution was observed with $100 \mu \mathrm{M} 3$. Compound 1 was unique in inducing the formation of a sub-G1

Table 2. Colorectal tumour cell growth inhibition by 6aminopyrimidines

\begin{tabular}{|c|c|c|}
\hline Compound & $\mathrm{Gl}_{50} \mathrm{HCT} 116(\mu \mathrm{M})$ & $\mathrm{Gl}_{50} \mathrm{HT} 29(\mu \mathrm{M})$ \\
\hline 1 & $4.3 \pm 2.6$ & $12 \pm 3$ \\
\hline 2 & $6.2 \pm 1.8$ & $12 \pm 4$ \\
\hline 7 & $73 \pm 28$ & $>100 \mu \mathrm{m}(30 \%)$ \\
\hline 6 & $>100 \mu \mathrm{M}(35 \%)$ & $>100 \mu \mathrm{M}(1 \%)$ \\
\hline 4 & $64 \pm 18$ & $44 \pm 5$ \\
\hline 5 & $6.7 \pm 1.8$ & $14 \pm 6$ \\
\hline 8 & $52 \pm 11$ & $59 \pm 20$ \\
\hline 3 & $>100 \mu \mathrm{M}(30 \%)$ & $>100 \mu \mathrm{M}(17 \%)$ \\
\hline Dactolisib (NVP-BEZ235) & $0.016 \pm 0.008$ & $0.014 \pm 0.001$ \\
\hline Rapamycin & $2.3 \pm 1.5$ & $4.2 \pm 1.4$ \\
\hline NU6102 & $5.7 \pm 0.4$ & $13.3 \pm 3.4$ \\
\hline Pictilisib (GDC-0941) & $1.7 \pm 0.3$ & $0.25 \pm 0.13$ \\
\hline
\end{tabular}

fraction, indicative of apoptosis (Figure 1). Further analysis of the effect of $\mathbf{1}$ on the cell cycle indicated that the sub-G1 fraction became apparent from $3 \mathrm{~h}$ onwards in HCT116 cells (Figure 1B). The increase in the sub-G1 fraction was significant after $3 \mathrm{~h}$ $(P=0.013)$ and remained significant up to $8 \mathrm{~h}(P<0.002)$. The $\mathrm{G} 1$ fraction was reduced after $4 \mathrm{~h}$ exposure to $\mathbf{1}$, but was only significant at the $10 \%$ level $(P<0.09)$, whereas the $\mathrm{S}$-phase fraction was significantly reduced at $4 \mathrm{~h}(P<0.016)$. The increase in the G2/ $\mathrm{M}$ phase fraction was significant at both 4 and $6 \mathrm{~h}(P<0.011)$. In HT29 cells, 1 induced a time-dependent increase in the G2/M fraction, with a sub-G1 fraction becoming apparent from $6 \mathrm{~h}$ onwards (Figure 1C), which was concentration-dependent at $24 \mathrm{~h}$ (Supplementary Figure 2). Although a sub-G1 fraction was apparent at 6 and $8 \mathrm{~h}$, this was not significant $(P=0.183$ at $8 \mathrm{~h})$; whereas the G1 fraction was significantly reduced after $4 \mathrm{~h}$ $(P<0.002)$. The S-phase fraction in HT29 cells was significantly reduced after $6 \mathrm{~h}(P<0.04)$ treatment with 1 , and the $\mathrm{G} 2 / \mathrm{M}$ fraction was significantly increased after $4 \mathrm{~h}(P<0.002)$.

To determine whether the sub-G1 fraction observed following treatment with 1 reflected cytotoxicity, clonogenic survival assays were performed in HCT116 and HT29 cells following an $8 \mathrm{~h}$ exposure. Compound 1 reduced the clonogenic survival of cells in a concentration-dependent manner in both HCT116 and HT29 cells (Figure 2A and B), with 50\% inhibition of colony formation at $5 \mu \mathrm{M}$. Consistent with the lack of a sub-G1 peak in flow cytometry experiments, the other pyrimidine inhibitors were not cytotoxic in either cell line even after $72 \mathrm{~h}$ exposure (HCT116 cells; Figure 2C).

To explore the contribution of CDK2 inhibition to the cytotoxicity of $\mathbf{1}$, the effects of $\mathbf{1}$ and $\mathbf{5}$ on target protein phosphorylation were examined in HCT116 (Figure 3) and HT29 (Supplementary Figure 3) cells following 4, 8 and $24 \mathrm{~h}$ exposure. Compound $\mathbf{5}$ was selected as being equipotent to $\mathbf{1}$ against PI3Ks and mTOR, with similar growth inhibitory potency in both cell lines but 600000 -fold less active against CDK2
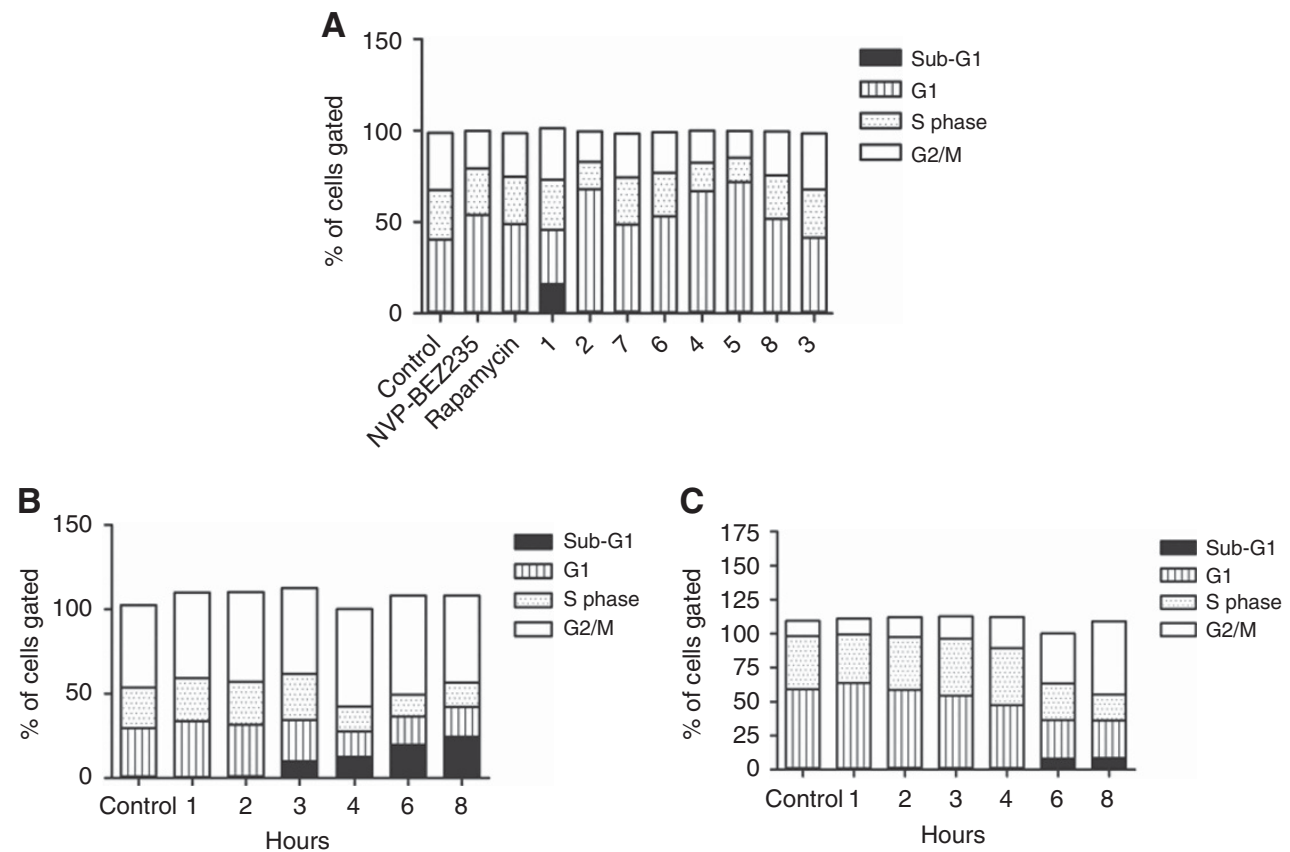

Figure 1. Cell cycle phase analysis following exposure to 6-aminopyrimidine inhibitors measured by flow cytometry. (A) HCT116 cells were treated with $\mathrm{Gl}_{50}$ concentrations of inhibitors (or $100 \mu \mathrm{M}$, Table 2) for $24 \mathrm{~h}$ then fixed, stained with propidium iodide and analysed by flow cytometry. Cell cycle phase distribution was analysed by WinMDI software, and the mean cell cycle fraction of cells gated into each phase of the cell cycle shown. (B) HCT116 cells were treated with the $\mathrm{G} \mathrm{I}_{50}$ concentration of 1 for up to $8 \mathrm{~h}$ and fixed at time points indicated before being stained with propidium iodide and analysed by flow cytometry. (C) HT29 cells were treated with the Gl 50 concentration of 1 for up to $8 \mathrm{~h}$ and fixed at the time points shown before being stained with propidium iodide and analysed by flow cytometry. Data are representative of duplicate experiments. 

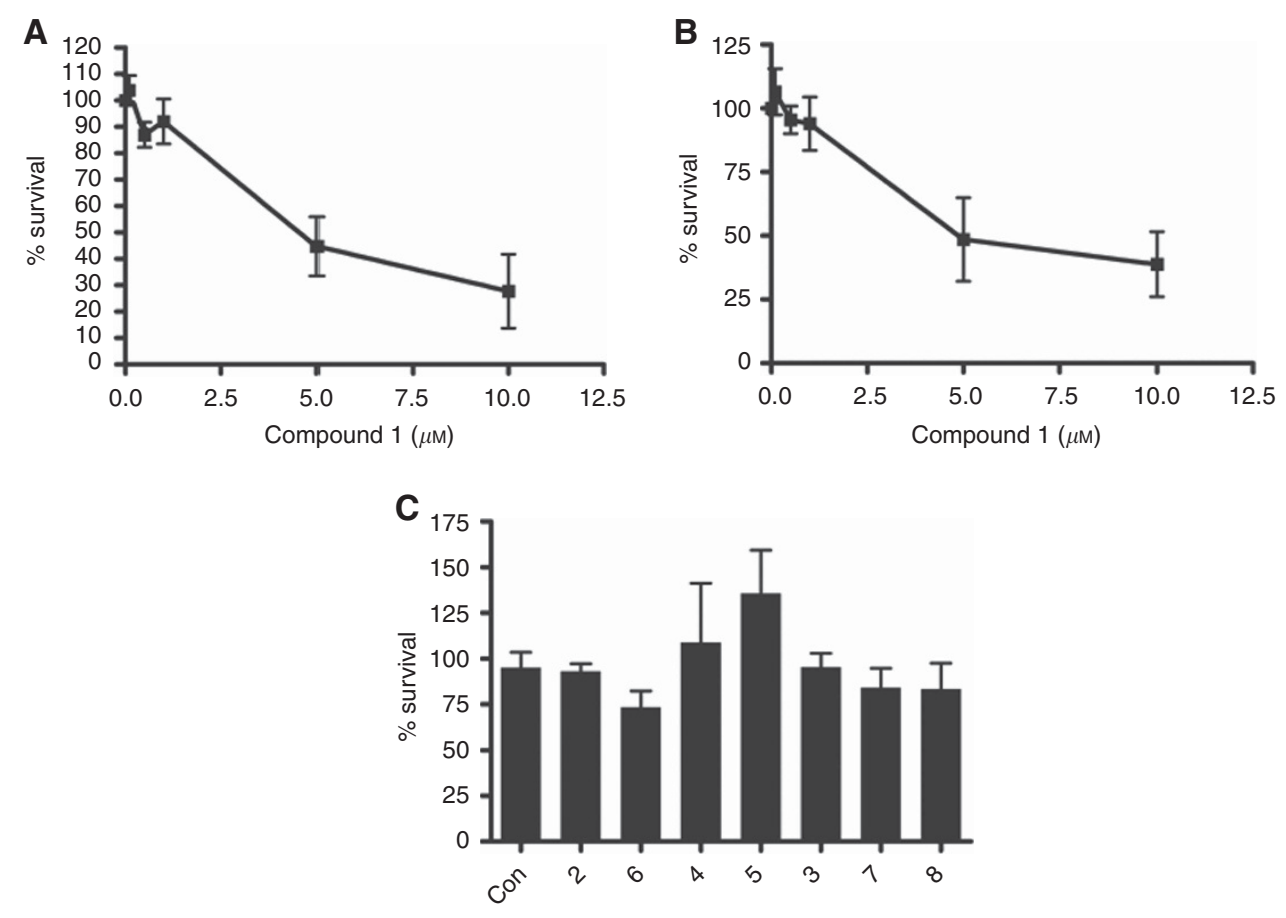

Figure 2. Effects of 6-aminopyrimidine inhibitors on the clonogenic survival of HCT116 and HT29 colorectal cancer cells. (A) HCT116 cells were treated with increasing concentrations of 1 for $8 \mathrm{~h}$. The medium was replaced with normal growth medium and the cells allowed to form colonies for 1 week. Colonies were stained with $0.4 \%(v / v)$ crystal violet and counted. (B) HT29 cells were treated as described in (A). (C) HCT116 cells were treated with the $\mathrm{Gl}_{50}$ concentration (or $100 \mu \mathrm{m}$, Table 2) of the 6-aminopyrimidine inhibitors for $72 \mathrm{~h}$ before being re-plated for analysis of colony formation as described in (A). All experiments were performed in triplicate and the data are the mean \pm s.d.
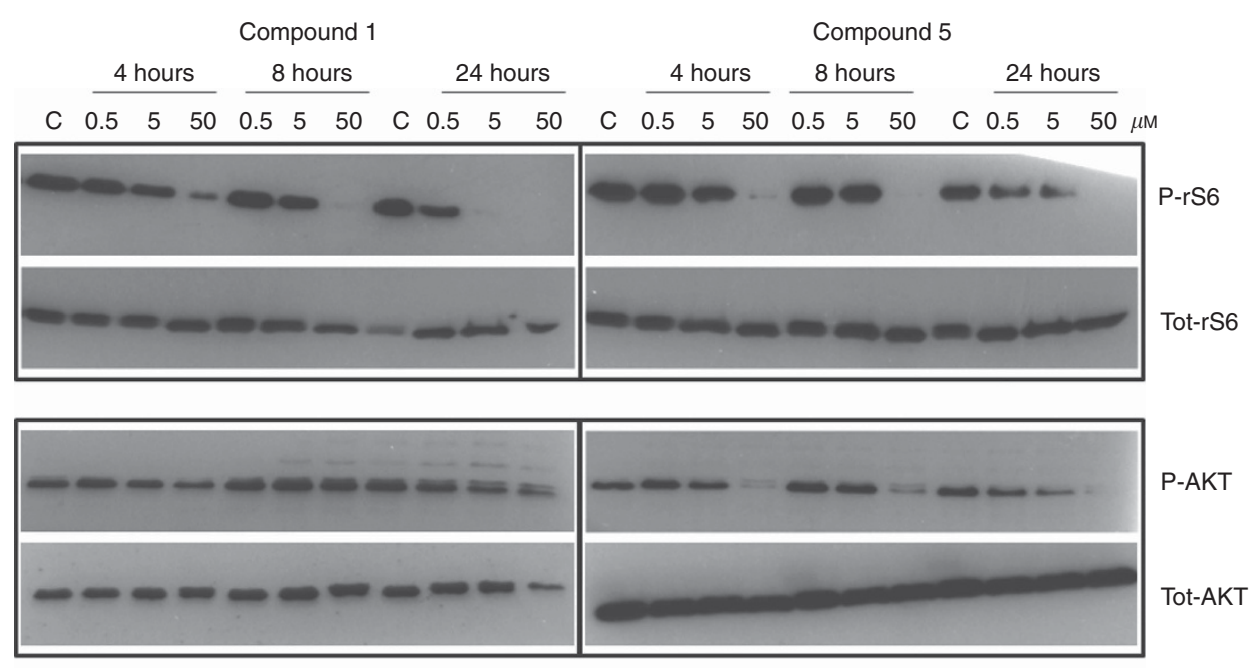

P-AKT

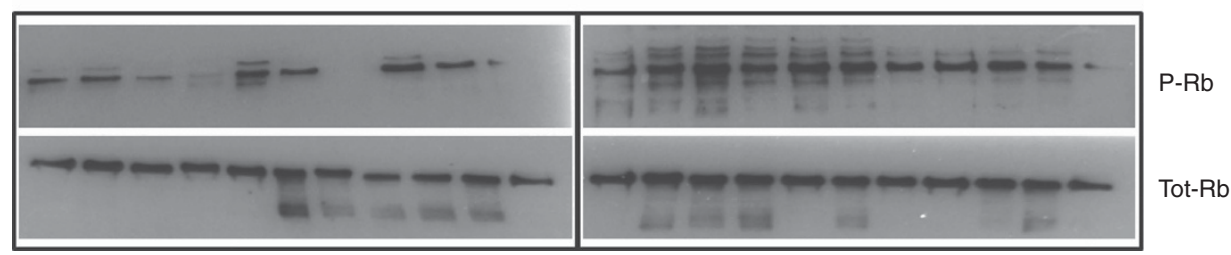

Figure 3. Effects of compounds 1 and 5 on the phosphorylation of rS6, AKT and Rb in HCT116 cells. HCT116 cells were treated with 1 or 5 for 4 , 8 or $24 \mathrm{~h}$ at $0.5,5$ or $50 \mu \mathrm{m}$. Protein was extracted and $30 \mu \mathrm{g}$ resolved on a $4-20 \%(\mathrm{w} / \mathrm{v})$ tris/glycine SDS-PAGE. Immuno-blotted membranes were probed with total and phospho-rS6, AKT and Rb antibodies and the western blots shown are representative of at least three experiments.

(Tables 1 and 2). Compound $\mathbf{1}$ induced concentration-dependent inhibition of Rb phosphorylation in HCT116 cells, with inhibition at a $\mathrm{GI}_{50}$ concentration of $5 \mu \mathrm{m}$ being observed at all time points, and at $24 \mathrm{~h}$ in HT29 cells. In contrast, the effect of $\mathbf{5}$ on Rb phosphorylation was less pronounced and only clearly observed after $24 \mathrm{~h}$ exposure to $50 \mu \mathrm{m}$. Compounds $\mathbf{1}$ and $\mathbf{5}$ had similar effects on rS6 phosphorylation in both cell lines, and only 5 consistently reduced AKT phosphorylation at $50 \mu \mathrm{M}$. 

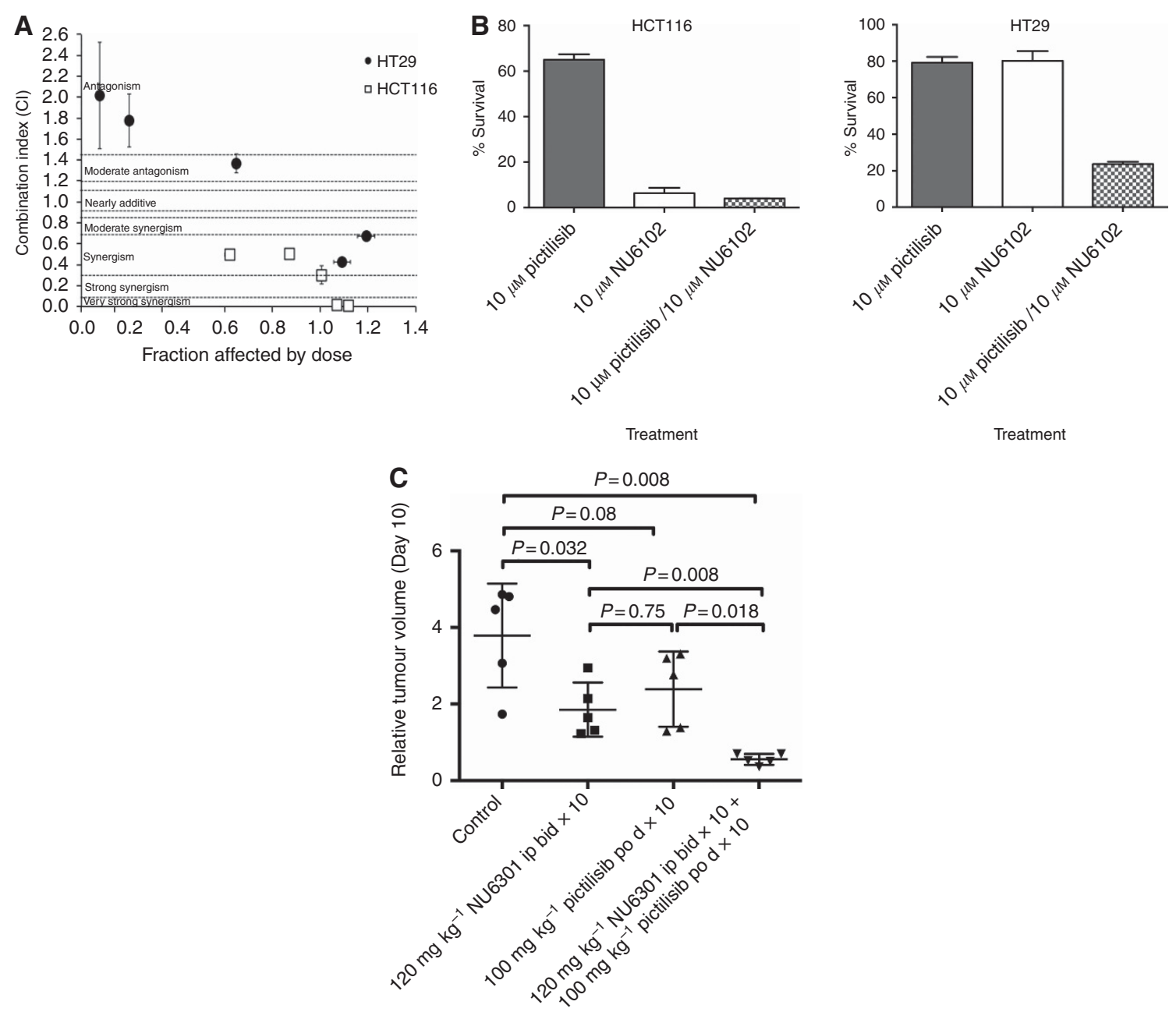

Figure 4. The impact of combined CDK2 and PI3K inhibition on colorectal tumour cell growth and survival in vitro, and HT29 tumour growth in vivo. (A) HCT116 or HT29 cells were exposed to combinations of NU6102 and pictilisib at fixed ratios $(0.25 \times, 0.5 \times, 1 \times, 2 \times$ and $4 \times)$ of their respective $\mathrm{Gl}_{50}$ concentrations (NU6102: HCT116 $5.7 \mu \mathrm{m}, \mathrm{HT29} 13 \mu \mathrm{m}$; pictilisib: HCT116 $1.7 \mu \mathrm{m}, \mathrm{HT29} 0.25 \mu \mathrm{m}$ ) and cell growth inhibition evaluated by median effect analysis. (B) Cytotoxicity of $1 \mu \mathrm{m}$ or $10 \mu \mathrm{m} \mathrm{NU6102}$ and pictilisib alone and in combination in HCT116 and HT29 colorectal tumour cell lines. (C) Efficacy of the NU6102 prodrug NU6301 and pictilisib, alone and in combination, in HT29 human colorectal tumour xenograft bearing mice. Mice were treated with vehicle (control), NU6301 $120 \mathrm{mg} \mathrm{kg}^{-1}$ i.p. (equivalent to $100 \mathrm{mg} \mathrm{kg}^{-1}$ NU6102) twice daily, $100 \mathrm{mg} \mathrm{kg}^{-1}$ pictilisib p.o. once daily, or the combination of twice daily NU6301 (120 mg kg ${ }^{-1}$ i.p.) and once daily pictilisib (100 $\mathrm{mg} \mathrm{kg}^{-1}$ p.o.) for 10 days. Data are the relative tumour volume (RTV) at the end of treatment (day 10) and P-values are the statistical differences between the groups as indicated by the Mann-Whitney test.

The results obtained with compound $\mathbf{1}$ in comparison with the other compounds suggested that dual CDK2 and PI3K inhibition resulted in cytotoxicity, and to confirm this suggestion studies were performed with the potent CDK2 inhibitor NU6102 (4-[[6(cyclohexylmethoxy)-9H-purin-2-yl]amino]-benzenesulfonamide) (Davies et al, 2002) in combination with the pan-PI3K inhibitor pictilisib. As shown in Figure 4A, the combination of NU6102 and pictilisib was synergistic in growth inhibition studies in both the HCT116 and HT29 cell lines. Furthermore, the combination of the two drugs at $10 \mu \mathrm{M}$ was cytotoxic to HT29 cells, which was significantly enhanced compared with either compound alone at this concentration (Figure 4B; $P \leqslant 0.0001$ ). However, in the HCT116 cell line, there was only a significant increase in cytotoxicity with the combination compared to pictilisib alone $(P \leqslant 0.0001)$, as NU6102 was cytotoxic as a single agent (Figure 4B).

An in vivo tumour growth inhibition study was performed using the HT29 model treated for 10 days with the NU6102 prodrug NU6301 at $120 \mathrm{mg} \mathrm{kg}^{-1}$ twice each day (equivalent to $100 \mathrm{mg} \mathrm{kg}^{-1} \mathrm{NU6102)}$, pictilisib (GDC-0941) at $100 \mathrm{mg} \mathrm{kg}^{-1}$ per day or the combination of the two drugs at these doses, which were based on in vivo pharmacodynamic data from earlier studies (Thomas et al, 2011; Haagensen et al, 2013). Compound 1 was not suitable for in vivo studies as it contains a 5-nitroso group, which is notoriously metabolically labile and potentially reactive. As shown in Figure 4C, RTV in mice treated with the combination of NU6301 and pictilisib (GDC-0941) were significantly lower in comparison with either of the drugs alone $(P=0.008$ and $P=0.018$, respectively, Mann-Whitney test) at the end of treatment (day 10). There was no tumour growth in the combination group while on treatment, whereas single-agent treatment at the doses used only generated growth delays, which were not significant in the case of NU6301 alone (time to RTV4 vs control $-P=0.13$, Mann-Whitney test), and not highly significant in the case of pictilisib (GDC-0941; time to RTV4 vs control $P=0.026$, Mann-Whitney test). In contrast, growth delay was highly significant for the combination therapy (time to RTV4 vs control $-P=0.0043$, Mann-Whitney test). Although a formal toxicology study was not performed, the combination treatment was well tolerated with no consistent impact of single-agent or combination drug treatment on body weights or clinical condition. 


\section{DISCUSSION}

Inhibitors of mTOR, PI3K and CDK2 are currently in various stages of clinical development. Extensive preclinical studies indicate that combinations of targeted agents may demonstrate greater antitumour activity and selectivity than single agents, the combination of PI3K and MEK inhibitors being an excellent example (Engelman et al, 2008; Haagensen et al, 2012; Haagensen et al, 2013). Counter-screening of compounds synthesised to target CDK2 identified a number of pyrimidines that were able to inhibit $\mathrm{PI} 3 \mathrm{~K}$ and/or mTOR, and we evaluated inhibitors with a range of potencies against CDK2, PI3K and mTOR for their effects on cell growth, cell cycle phase distribution and cytotoxicity.

In the two colorectal cancer cell lines studied, HCT116 and HT29, three of the compounds had $\mathrm{GI}_{50}$ values of $<20 \mu \mathrm{M}$ : 1, 2 and 5. The wide range of potencies of these compounds as inhibitors of $\operatorname{CDK} 2(0.1,2200$ and $60000 \mathrm{~nm}$, respectively) and the lack of activity against mTOR of two of the compounds $(<5 \%$ inhibition at $20 \mu \mathrm{M}: 1$ and 5), yet similar potency for PI3K inhibition, is not inconsistent with growth inhibition owing to activity against the latter targets. The reduced growth inhibitory properties on $4,6,7$ and 8 , despite similar potency against PI3Ks to 1,2 and 5, may be due to reduced cellular uptake resulting from the major structural changes at the 4-position (replacement of the cyclohexylmethyl group in $6,7,8$ ) or 5-position (replacement of the nitroso group with formyl in 4). In this latter regard, removal of the 5-nitroso group (3) resulted in complete loss of activity against CDK2 and PI3Ks; however, interestingly, modest mTOR inhibition was retained. Nevertheless, despite the mTOR inhibitory activity of 3 , the compound did not inhibit cell growth. The reason for the lack of CDK2 inhibition by 3 can be explained by the absence of an intra-molecular hydrogen bond as in $\mathbf{1}$ (i.e., between the 5-nitroso and the 6-amino group), which is critical for maintaining the correct orientation of the 6-amino group for hydrogen bonding to Glu-81 of CDK2 (Arris et al, 2000). A similar effect may explain the lack of activity of 3 against PI3Ks, although there are no structural data to support this contention.

When asynchronous cell cultures were treated with $\mathrm{GI}_{50}$ concentrations of the growth inhibitory compounds the predominant effect was an accumulation of cells in the G1 phase of the cell cycle. Both rapamycin and dactolisib (NVP-BEZ235) also caused a G1 arrest at their $\mathrm{GI}_{50}$ concentrations, an effect that has been previously reported with PI3K and/or mTOR inhibitors (Mita et al, 2003; Serra et al, 2008). In contrast to the other growth inhibitory compounds, 1 initially either had no effect on the fraction of cells in the G1 phase (HCT116) or reduced the size of the G1 fraction (HT29), before rapidly ( $\leqslant 6 \mathrm{~h})$ inducing a sub-G1 population in both cell lines indicative of apoptosis, although only significantly in the HCT116 cells. The impact of the apoptosis induced by 1 was revealed by clonogenic cytotoxicity studies where the compound was shown to be cytotoxic to both HCT116 and HT29 cells following exposure for $8 \mathrm{~h}$ at growth inhibitory concentrations. In marked contrast, exposure of HCT116 cells for $72 \mathrm{~h}$ to all of the other pyrimidines failed to induce significant cytotoxicity. Together, these cellular data suggest that the potent CDK2 inhibitory activity of $\mathbf{1}$ contributes to the cytotoxic activity of the compound.

To evaluate whether the relative potencies of compounds against purified kinases reflected their activity in a cellular context, western blotting experiments were performed with $\mathbf{1}$ and the nonCDK2 inhibitory control compound, 5. As expected, 1 inhibited the phosphorylation of the CDK2 substrate $\mathrm{Rb}$ at earlier time points and at lower concentrations than 5, and these data are consistent with the hypothesis that the apoptosis and cytotoxicity induced by $\mathbf{1}$ is related to CDK2 inhibition. Interestingly, despite good inhibition of rS6 phosphorylation, compound $\mathbf{1}$ did not inhibit the phosphorylation of AKT, which is likely to reflect phosphorylation at this site by other pathways, for example, IKK has recently been implicated in promoting AKT phosphorylation at Ser473 (Dan et al, 2016).

To confirm that the cytotoxicity observed with 1 was due to dual CDK2 and PI3K inhibition, combination studies were performed with the potent and selective CDK2 inhibitor NU6102 in combination with the pan-PI3K inhibitor pictilisib. In growth inhibition studies, a synergistic as opposed to an additive interaction was observed, particularly in the HCT116 cell line, and in cytotoxicity studies combination of the two inhibitors was markedly more cytotoxic in HT29 cells than either compound alone. Importantly, the superior activity of the combination of the CDK2 and the PI3K inhibitor was recapitulated in an in vivo antitumour study without any marked increase in host toxicity, as evaluated by body weight changes and clinical observations. The specificity of NU6102 as a CDK2 inhibitor has been wellestablished (Davies et al, 2002) and confirmed subsequently in a study using CDK2 WT and KO MEFs (Thomas et al, 2011). At the concentrations and doses of NU6102 used in the current study (10 $\mu \mathrm{M}$ in vitro and $100 \mathrm{mg} \mathrm{kg}^{-1}$ in vivo), these previous studies have demonstrated CDK2 specificity (Davies et al, 2002; Thomas et al, 2011). Pictilisib is a very widely used and well-characterised PI3K inhibitor, and was used at doses and concentrations in line with previous published studies (Haagensen et al, 2012; Haagensen et al, 2013). Consequently, these tool compounds can be used to show that dual CDK2 and PI3K inhibition may represent an approach to improving antitumour selectivity with these two classes of targeted agents.

Mechanistically, the potential of dual CDK2 and PI3K pathway inhibition has been highlighted by a number of studies. Initially, Maddika et al, 2008 demonstrated that nuclear translocation of $\mathrm{AKT}$ results in phosphorylation of $\mathrm{CDK} 2 /$ cyclin $\mathrm{A}$, leading to cytoplasmic redistribution of $\mathrm{CDK} 2 /$ cyclin $\mathrm{A}$, which was required for $S$ to $\mathrm{G} 2-\mathrm{M}$ cell cycle phase progression. Subsequently, a landmark paper (Liu et al, 2014) reported that phosphorylation of AKT by CDK2/cyclinA2 at S477/T479 was a critical priming event that precedes AKT activation by phosphorylation at the canonical S473 locus, and that by this mechanism CDK2/cyclinA1 activity is a prerequisite for the oncogenic activity of AKT and hence more generally the PI3K pathway. These recent mechanistic insights into the interplay between CDK2 and PI3K signalling provide a rationale for the improved activity of dual CDK2 and PI3K inhibition described in the current paper. Furthermore, the effects of the dual pyrimidine-based inhibitor $\mathbf{1}$ and combined treatment with the selective CDK2 antagonist NU6102 and the pan-PI3K inhibitor pictilisib described here are consistent with the results using alternative small molecule CDK and PI3K inhibitors, and siRNA (Cheng et al, 2012). In this latter study, increased apoptosis in vitro and enhanced tumour growth delay in vivo were observed when both CDK2 and PI3K, specifically $\mathrm{PI} 3 \mathrm{~K} \alpha$, were modulated by chemical and/or molecular genetic means.

In summary, we have synthesised and characterised a series of 6-aminopyrimidines identified from a kinase screen that are inhibitors of PI3K and/or mTOR and/or CDK2. In HCT116 and HT29 cell lines, PI3K inhibition is associated with cell growth inhibition, regardless of the activity against CDK2. Likewise, the level of mTOR inhibition does not influence cell growth inhibitory potency. Importantly, the mixed CDK2 and PI3K inhibitor 1 induces apoptosis and is cytotoxic, suggesting that dual CDK2/ PI3K targeting may be preferential to inhibition of either enzyme alone. Mechanistically, the recent identification of direct interactions between CDK2 and AKT, the proximal downstream target of PI3K signalling, provides a rationale for the simultaneous targeting of the CDK2 and the PI3K pathway in order to achieve maximal antitumour effects. 


\section{ACKNOWLEDGEMENTS}

PI3K and mTOR assays were performed at UCB Celltech and we thank UCB Pharmaceuticals scientists Andrew Gill and Tom Crabbe for the development of these assays. GB, HDT, L-Z W, BTG, IRH, DRN, RJG and CC were funded by a CR UK Drug Discovery Programme (C240/A7409), CHR was a PhD Student funded by CR UK (C8120/A8000), SLP was funded by a CR UK Medicinal Chemistry Training Programme (C129/A6963) and EJH was an MRC CASE Award PhD Student supported by UCB Celltech.

\section{CONFLICT OF INTEREST}

The authors declare no conflict of interest.

\section{REFERENCES}

Aleem E, Berthet C, Kaldis P (2004) Cdk2 as a master of S phase entry: fact or fake? Cell Cycle 3(1): 35-37.

Arris CE, Boyle FT, Calvert AH, Curtin NJ, Endicott JA, Garman EF, Gibson AE, Golding BT, Grant S, Griffin RJ, Jewsbury P, Johnson LN, Lawrie AM, Newell DR, Noble ME, Sausville EA, Schultz R, Yu W (2000) Identification of novel purine and pyrimidine cyclin-dependent kinase inhibitors with distinct molecular interactions and tumor cell growth inhibition profiles. J Med Chem 43(15): 2797-2804.

Asghar U, Witkiewicz AK, Turner NC, Knudsen ES (2015) The history and future of targeting cyclin-dependent kinases in cancer therapy. Nat Rev Drug Discov 14(2): 130-146.

Brachmann S, Fritsch C, Maira SM, Garcia-Echeverria C (2009) PI3K and mTOR inhibitors: a new generation of targeted anticancer agents. Curr Opin Cell Biol 21(2): 194-198.

Cairns P, Okami K, Halachmi S, Halachmi N, Esteller M, Herman JG, Jen J, Isaacs WB, Bova GS, Sidransky D (1997) Frequent inactivation of PTEN/ MMAC1 in primary prostate cancer. Cancer Res 57(22): 4997-5000.

Cancer Genome Atlas Research Network (2008) Comprehensive genomic characterization defines human glioblastoma genes and core pathways. Nature 455(7216): 1061-1068.

Celebi JT, Shendrik I, Silvers DN, Peacocke M (2000) Identification of PTEN mutations in metastatic melanoma specimens. J Med Genet 37(9): 653-657.

Cheng CK, Gustafson WC, Charron E, Houseman BT, Zunder E, Goga A, Gray NS, Pollok B, Oakes SA, James CD, Shokat KM, Weiss WA, Fan QW (2012) Dual blockade of lipid and cyclin-dependent kinases induces synthetic lethality in malignant glioma. Proc Natl Acad Sci USA 109(31): 12722-12727.

Chiarini F, Evangelisti C, McCubrey JA, Martelli AM (2015) Current treatment strategies for inhibiting mTOR in cancer. Trends Pharmacol Sci 36(2): 124-135.

Condliffe AM, Davidson K, Anderson KE, Ellson CD, Crabbe T, Okkenhaug K, Vanhaesebroeck B, Turner M, Webb L, Wymann MP, Hirsch E, Ruckle T, Camps M, Rommel C, Jackson SP, Chilvers ER, Stephens LR, Hawkins PT (2005) Sequential activation of class IB and class IA PI3K is important for the primed respiratory burst of human but not murine neutrophils. Blood 106(4): 1432-1440.

Dan HC, Antonia RJ, Baldwin AS (2016) PI3K/Akt promotes feedforward mTORC2 activation through IKKalpha. Oncotarget 7(16): 21064-21075.

Davies TG, Bentley J, Arris CE, Boyle FT, Curtin NJ, Endicott JA, Gibson AE, Golding BT, Griffin RJ, Hardcastle IR, Jewsbury P, Johnson LN, Mesguiche V, Newell DR, Noble ME, Tucker JA, Wang L, Whitfield HJ (2002) Structure-based design of a potent purine-based cyclin-dependent kinase inhibitor. Nat Struct Biol 9(10): 745-749.

Engelman JA (2009) Targeting PI3K signalling in cancer: opportunities, challenges and limitations. Nat Rev Cancer 9(8): 550-562.

Engelman JA, Chen L, Tan X, Crosby K, Guimaraes AR, Upadhyay R, Maira M, McNamara K, Perera SA, Song Y, Chirieac LR, Kaur R, Lightbown A, Simendinger J, Li T, Padera RF, Garcia-Echeverria C, Weissleder R,
Mahmood U, Cantley LC, Wong K-K (2008) Effective use of PI3K and MEK inhibitors to treat mutant Kras G12D and PIK3CA H1047R murine lung cancers. Nat Med 14(12): 1351-1356.

Garcia JM, Silva JM, Dominguez G, Gonzalez R, Navarro A, Carretero L, Provencio M, Espana P, Bonilla F (1999) Allelic loss of the PTEN region (10q23) in breast carcinomas of poor pathophenotype. Breast Cancer Res Treat 57(3): 237-243.

Haagensen EJ, Kyle S, Beale GS, Maxwell RJ, Newell DR (2012) The synergistic interaction of MEK and PI3K inhibitors is modulated by mTOR inhibition. Br J Cancer 106(8): 1386-1394.

Haagensen EJ, Thomas HD, Wilson I, Harnor SJ, Payne SL, Rennison T, Smith KM, Maxwell RJ, Newell DR (2013) The enhanced in vivo activity of the combination of a MEK and a PI3K inhibitor correlates with [18F]FLT PET in human colorectal cancer xenograft tumour-bearing mice. PLoS One 8(12): e81763.

Harbour JW, Luo RX, Dei Santi A, Postigo AA, Dean DC (1999) Cdk phosphorylation triggers sequential intramolecular interactions that progressively block $\mathrm{Rb}$ functions as cells move through G1. Cell 98(6): 859-869.

Harrington LS, Findlay GM, Lamb RF (2005) Restraining PI3K: mTOR signalling goes back to the membrane. Trends Biochem Sci 30(1): 35-42.

Lannutti BJ, Meadows SA, Herman SEM, Kashishian A, Steiner B, Johnson AJ, Byrd JC, Tyner JW, Loriaux MM, Deininger M, Druker BJ, Puri KD, Ulrich RG, Giese NA (2011) CAL-101, a p110delta selective phosphatidylinositol-3-kinase inhibitor for the treatment of B-cell malignancies, inhibits PI3K signaling and cellular viability. Blood 117(2): 591-594.

Lin TS, Ruppert AS, Johnson AJ, Fischer B, Heerema NA, Andritsos LA, Blum KA, Flynn JM, Jones JA, Hu W, Moran ME, Mitchell SM, Smith LL, Wagner AJ, Raymond CA, Schaaf LJ, Phelps MA, Villalona-Calero MA, Grever MR, Byrd JC (2009) Phase II study of flavopiridol in relapsed chronic lymphocytic leukemia demonstrating high response rates in genetically high-risk disease. J Clin Oncol 27(35): 6012-6018.

Liu P, Begley M, Michowski W, Inuzuka H, Ginzberg M, Gao D, Tsou P, Gan W, Papa A, Kim BM, Wan L, Singh A, Zhai B, Yuan M, Wang Z, Gygi SP, Lee TH, Lu KP, Toker A, Pandolfi PP, Asara JM, Kirschner MW, Sicinski P, Cantley L, Wei W (2014) Cell-cycle-regulated activation of Akt kinase by phosphorylation at its carboxyl terminus. Nature 508(7497): 541-545.

Maddika S, Ande SR, Wiechec E, Hansen LL, Wesselborg S, Los M (2008) Akt-mediated phosphorylation of CDK2 regulates its dual role in cell cycle progression and apoptosis. J Cell Sci 121(Pt 7): 979-988.

Marchetti F, Cano C, Curtin NJ, Golding BT, Griffin RJ, Haggerty K, Newell DR, Parsons RJ, Payne SL, Wang LZ, Hardcastle IR (2010) Synthesis and biological evaluation of 5-substituted O4-alkylpyrimidines as CDK2 inhibitors. Org Biomol Chem 8(10): 2397-2407.

Mayer IA, Arteaga CL (2015) The PI3K/AKT pathway as a target for cancer treatment. Annu Rev Med 67: 11-28.

Menon S, Manning BD (2008) Common corruption of the mTOR signaling network in human tumors. Oncogene 27(Suppl 2): S43-S51.

Mesguiche V, Parsons RJ, Arris CE, Bentley J, Boyle FT, Curtin NJ, Davies TG, Endicott JA, Gibson AE, Golding BT, Griffin RJ, Jewsbury P, Johnson LN, Newell DR, Noble ME, Wang LZ, Hardcastle IR (2003) 4-Alkoxy-2,6diaminopyrimidine derivatives: inhibitors of cyclin dependent kinases 1 and 2. Bioorg Med Chem Lett 13(2): 217-222.

Mita MM, Mita A, Rowinsky EK (2003) The molecular target of rapamycin (mTOR) as a therapeutic target against cancer. Cancer Biol Ther 2(4 Suppl 1): S169-S177.

Rocca A, Farolfi A, Bravaccini S, Schirone A, Amadori D (2014) Palbociclib (PD 0332991): targeting the cell cycle machinery in breast cancer. Expert Opin Pharmacother 15(3): 407-420.

Satyanarayana A, Kaldis P (2009) Mammalian cell-cycle regulation: several Cdks, numerous cyclins and diverse compensatory mechanisms. Oncogene 28(33): 2925-2939.

Sayle KL, Bentley J, Boyle FT, Calvert AH, Cheng Y, Curtin NJ, Endicott JA, Golding BT, Hardcastle IR, Jewsbury P, Mesguiche V, Newell DR, Noble ME, Parsons RJ, Pratt DJ, Wang LZ, Griffin RJ (2003) Structure-based design of 2-arylamino-4-cyclohexylmethyl-5-nitroso-6-aminopyrimidine inhibitors of cyclin-dependent kinases 1 and 2. Bioorg Med Chem Lett 13(18): 3079-3082.

Serra V, Markman B, Scaltriti M, Eichhorn PJA, Valero V, Guzman M, Botero ML, Llonch E, Atzori F, Di Cosimo S, Maira M, Garcia-Echeverria C, Parra JL, Arribas J, Baselga J (2008) NVP-BEZ235, a dual PI3K/mTOR 
inhibitor, prevents PI3K signaling and inhibits the growth of cancer cells with activating PI3K mutations. Cancer Res 68(19): 8022-8030.

Shapiro GI (2006) Cyclin-dependent kinase pathways as targets for cancer treatment. J Clin Oncol 24(11): 1770-1783.

Stemke-Hale K, Gonzalez-Angulo AM, Lluch A, Neve RM, Kuo WL, Davies M, Carey M, Hu Z, Guan Y, Sahin A, Symmans WF, Pusztai L, Nolden LK, Horlings H, Berns K, Hung MC, van de Vijver MJ, Valero V, Gray JW, Bernards R, Mills GB, Hennessy BT (2008) An integrative genomic and proteomic analysis of PIK3CA, PTEN, and AKT mutations in breast cancer. Cancer Res 68(15): 6084-6091.

Thomas HD, Wang LZ, Roche C, Bentley J, Cheng Y, Hardcastle IR, Golding BT, Griffin RJ, Curtin NJ, Newell DR (2011) Preclinical in vitro and in vivo evaluation of the potent and specific cyclin-dependent kinase 2 inhibitor NU6102 and a water soluble prodrug NU6301. Eur J Cancer 47(13): 2052-2059.

Yap TA, Bjerke L, Clarke PA, Workman P (2015) Drugging PI3K in cancer: refining targets and therapeutic strategies. Curr Opin Pharmacol 23: 98-107.

This work is published under the standard license to publish agreement. After 12 months the work will become freely available and the license terms will switch to a Creative Commons AttributionNonCommercial-Share Alike 4.0 Unported License.

Supplementary Information accompanies this paper on British Journal of Cancer website (http://www.nature.com/bjc) 